Published in final edited form as:

J Am Chem Soc. 2005 November 30; 127(47): 16414-16415.

\title{
Intrinsic Isotope Effects on Benzylic Hydroxylation by the Aromatic Amino Acid Hydroxylases: Evidence for Hydrogen Tunneling, Coupled Motion, and Similar Reactivities
}

\author{
Jorge Alex Pavon $\ddagger$ and Paul F. Fitzpatrick ${ }^{\star}, \ddagger, \S$ \\ Departments of Biochemistry and Biophysics, and Department of Chemistry, Texas A\&M University, \\ College Station, Texas 77843-2128
}

Phenylalanine hydroxylase $(\mathrm{PheH})$, tyrosine hydroxylase $(\mathrm{TyrH})$, and tryptophanhydroxylase $(\mathrm{TrpH})$ form a small family of non-heme iron monooxygenases which catalyze the insertion of an oxygen atom from molecular oxygen into the aromatic side chain of their corresponding substrates using a tetrahydropterin to reduce the other oxygen atom to the level of water. ${ }^{1,2}$ Their catalytic domains are homologous, with each containing a single iron atom bound to two conserved histidines and a glutamate, suggesting that all three share a common catalytic mechanism. Despite the structural similarities, the three clearly differ in substrate specificities, in $k_{\text {cat }}$ values, and in the identity of the rate-determining step. ${ }^{1-4}$ All three catalyze benzylic hydroxylation of methylated aromatic amino acids. ${ }^{5-7}$ In the case of TyrH, the intrinsic kinetic isotope effects for this reaction are consistent with the removal of a hydrogen atom from the methyl group. ${ }^{6}$ In the present study, a detailed analysis of the intrinsic primary and $\alpha$-secondary deuterium isotope effects for benzylic hydroxylation by all three enzymes has been carried out as a probe of the relative reactivities of the iron centers.

Figure 1 shows the distribution of products when 4- $\mathrm{CH}_{3}$-phenylalanine is used as substrate for wild-type TyrH and $\mathrm{PheH}^{3}$ and for $\Delta 117 \mathrm{PheH}^{3}$ and $\mathrm{TrpH}_{102-416}, 4$ mutant forms of $\mathrm{PheH}$ and TrpH lacking the N-terminal regulatory domains. For PheH, the percentage of 3-HO-4- $\mathrm{CH}_{3}$ phenylalanine is extremely low, consistent with a strong preference of this enzyme for hydroxylation of the 4-position. The other two enzymes are less specific. Deletion of the regulatory domain of $\mathrm{PheH}$ has no effect on the product composition.

$$
\mathrm{D}\left(\% 4-\mathrm{CH}_{2} \mathrm{OH}-\mathrm{phe}\right)=\left(\mathrm{D}_{1}+k_{1 \mathrm{H}} / k_{2}\right) /\left(1+k_{1 \mathrm{H}} / k_{2}\right)(1)
$$

When 4- ${ }^{2} \mathrm{H}_{3}$-phenylalanine ${ }^{6}$ is used as substrate, there is a large decrease in the amount of benzylic hydroxylation and a commensurate increase in the amount of aromatic hydroxylation, such that the total amount of hydroxylated amino acids remains the same. The isotope effect on benzylic hydroxylation can be calculated from the change in product composition using the model shown in Scheme 1.8,9 Here, the different hydroxylated amino acid products are formed upon partitioning of the hydroxylating intermediate, proposed to be a ferryl-oxo species resembling that of the heme-based cytochrome $\mathrm{P} 450$ in reactivity. ${ }^{2,10}$ In this model, the

E-mail:fitzpat@tamu.edu.

*Departments of Biochemistry and Biophysics.

$\S$ Department of Chemistry.

Note Added after ASAP Publication. A change was made on revision in paragraph 5 that should have been made in paragraph 4 instead. After this paper was published ASAP November 2, 2005, the fourth and fifth paragraphs were corrected, and a correction was made to the labeling in Figure 1. The corrected version was published ASAP November 9, 2005.

Supporting Information Available: Arrhenius plots for TyrH, $\mathrm{PheH}$, and $\mathrm{TrpH}_{102-416}$, and tables of isotope effects and of the isotopic content of the hydroxymethylphenylalanine products. This material is available free of charge via the Internet at http://pubs.acs.org. 
fraction of 4- $\mathrm{HOCH}_{2}$-phenylalanine produced is $k_{1} /\left(k_{1}+k_{2}\right)$, and the isotope effect on the percent of benzylic hydroxylation is related to the intrinsic isotope effect on $k_{1}$ by eq 1 . The value of $k_{1 \mathrm{H}} / k_{2}$ is readily determined from the products with $4-\mathrm{CH}_{3}$-phenylalanine. The deuterium isotope effects for benzylic hydroxylation of $4-\mathrm{C}^{2} \mathrm{H}_{3}$-phenylalanine, ${ }^{\mathrm{D}} k_{1}$, by TyrH, $\mathrm{PheH}, \Delta 117 \mathrm{PheH}$, and $\mathrm{TrpH}_{102-416}$ are listed in Table 1 . The values for all the enzymes are similar.

A similar analysis was carried out with 4- $\mathrm{CH}_{3}$-phenylalanine containing one or two deuterium atoms in the methyl group; ${ }^{6}$ in each case, the decrease in benzylic hydroxylation was less than that seen for the trideuterated substrate, and the resulting isotope effects were also smaller. When the trideuterated substrate is used, hydroxylation requires that a carbon-deuterium bond be broken, and the deuterium isotope effect is a product of a primary and two $\alpha$-secondary effects, ${ }^{\mathrm{D}} k\left({ }^{\alpha \mathrm{D}} k\right)^{2}$. When the monodeuterated or dideuterated substrate is used, the product 4hydroxymethylphenylalanine can result from loss of deuterium or hydrogen, so that the observed isotope effects on product composition are more complex combinations of primary and secondary effects. These effects were deconvoluted by determining the relative amounts of hydrogen versus deuterium loss in the 4-hydroxymethylphenylalanine product. ${ }^{9-11}$ In the case of $4-\mathrm{CH}_{2}{ }^{2} \mathrm{H}$-phenylalanine, the ratio of $4-\mathrm{HOCH}^{2} \mathrm{H}$-phenylalanine to $4-\mathrm{HOCH}_{2}-$ phenylalanine is $2^{\mathrm{D}} k / \alpha \mathrm{D} k$. For $4-\mathrm{CH}^{2} \mathrm{H}_{2}$-phenylalanine, the ratio of the dideuterated to the monodeuterated product is ${ }^{D_{k}} / 2^{\alpha D_{k}}$. Consequently, the isotopic composition of the 4hydroxymethylphenylalanine and the intrinsic isotope effect on benzylic hydroxylation for the trideuterated substrate allows calculation of the intrinsic primary and secondary isotope effects. In addition, the results with the mono- and dideuterated substrates provide independent values. These intrinsic isotope effects are listed in Table 1 . The results from the two partially deuterated substrates are different, but similar results were obtained for all three enzymes. Intrinsic primary isotope effects of about 10 and $\alpha$-secondary isotope effects of about 1.1 were found with 4- $\mathrm{CH}_{2}{ }^{2} \mathrm{H}$-phenylalanine. In contrast, the use of $4-\mathrm{CH}^{2} \mathrm{H}_{2}$ - phenylalanine results in intrinsic primary isotope effects less than 8 and $\alpha$-secondary isotope effects of 1.3 or greater. These isotope effects are consistent with the previously proposed mechanism for benzylic hydroxylation, in which a hydrogen atom is abstracted in a transition sate with significant $\mathrm{sp}^{2}$ character. ${ }^{6}$ The isotope effects when one deuterium is present in the methyl group are likely to be the intrinsic effects. However, when a second deuterium is present, the motion of the primary hydrogen is coupled to the motion of the second deuterium, resulting in an inflated $\alpha$-secondary isotope effect and a decreased primary effect. ${ }^{12-14}$ The intrinsic primary and $\alpha$ secondary kinetic isotope effects for $\mathrm{TyrH}, \Delta 117 \mathrm{PheH}$, and $\mathrm{TrpH}_{102-416}$ are indistinguishable, suggesting that the transition states for $\mathrm{CH}$ bond cleavage are similar; this requires that the ferryl-oxo intermediates in all three have similar reactivities.

The intrinsic primary isotope effects with the monodeuterated substrate are greater than the upper limit of about 7 predicted by transition state theory. Such large kinetic isotope effects are often interpreted as indicating quantum mechanical tunneling of the hydrogen atom. ${ }^{15-}$ ${ }^{17}$ Figure 2 shows the temperature dependence of the intrinsic kinetic isotope effect for $\Delta 117 \mathrm{PheH}$. The data from this and similar analyses for $\mathrm{TyrH}, \mathrm{PheH}, \Delta 117 \mathrm{PheH}$, and $\mathrm{TrpH}_{102-416}$ were fit to the Arrhenius equation to obtain the isotope effects on the Arrhenius pre-exponential factors $\left(A_{\mathrm{H}} / A_{\mathrm{D}}\right)$ and the differences in activation energies $\left(\Delta E_{\mathrm{act}}\right)$. In the absence of tunneling, $A_{\mathrm{H}} / A_{\mathrm{D}}$ will fall in the range of 0.7-1.4, and $\Delta E_{\text {act }}$ should not exceed 1.4 $\mathrm{kcal} \mathrm{mol}{ }^{-1.16,18-20}$ For all three aromatic amino acid hydroxylases, the values of $A_{\mathrm{H}} / A_{\mathrm{D}}$ and $\Delta E_{\text {act }}$ are outside these ranges (Table 2). Since $A_{\mathrm{H}} / A_{\mathrm{D}}<0.7$, the tunneling can be described as moderate, with protium tunneling to a much greater extent than deuterium. ${ }^{17,21}$ The values for all three enzymes agree well, suggesting that the extent of tunneling is very similar.

The data presented here are consistent with all three aromatic amino acid hydroxylases catalyzing benzylic hydroxylation via hydrogen atom abstraction, with coupled motion and 
quantum mechanical tunneling contributions. The similarities of the isotope effects and of the contribution of tunneling suggest that the reactivities of the hydroxylating intermediates are very similar among the three enzymes, irrespective of the presence of a regulatory domain.

\section{Acknowledgements}

We thank Dr. Shane Tichy of the TAMU LBMS for assistance with the mass spectrometry, and Drs. Patrick Frantom and Graham Moran for the generous gifts of TyrH and $\mathrm{TrpH}_{102}-416$, respectively. This work was supported by NIH Grant GM47291 and Welch Foundation Grant A1245.

\section{References}

1. Fitzpatrick, P. F. In Advances in Enzymology and Related Areas of Molecular Biology; Purich, D. L., Ed.; John Wiley \& Sons: New York, 2000; Vol. 74, pp 235-294.

2. Fitzpatrick PF. Biochemistry 2003;42:14083-14091. [PubMed: 14640675]

3. Daubner SC, Hillas PJ, Fitzpatrick PF. Biochemistry 1997;36:11574-11582. [PubMed: 9305947]

4. Moran GR, Daubner SC, Fitzpatrick PF. J Biol Chem 1998;273:12259-12266. [PubMed: 9575176]

5. Moran GR, Phillips RS, Fitzpatrick PF. Biochemistry 1999;38:16283-16289. [PubMed: 10587452]

6. Frantom PA, Pongdee R, Sulikowski GA, Fitzpatrick PF. J Am Chem Soc 2002;124:4202-4203. [PubMed: 11960436]

7. Siegmund HU, Kaufman S. J Biol Chem 1991;266:2903-2910. [PubMed: 1993664]

8. Nelson D, Trager WF. Drug Metab Disp 2003;31:1481-1498.

9. Fitzpatrick, P. F. In Isotope Effects in Chemistry and Biology; Kohen, A., Limbach, H., Eds.; Marcel Dekker: New York, 2005; pp 861-873. This model assumes that the intial attack of the hydroxylating intermediate on the substrate is irreversible, so that there are no internal commitments in $\mathrm{k}_{1}$ or $\mathrm{k}_{2}$ This has not been explicitly established but is reasonable based on the following: (1) oxygenation reactions are typically irreversible; (2) the isotope effects are large; and (3) the Arhennius plots are linear over large temperature ranges.

10. Bassan A, Blomberg MRA, Siegbahn PEM. Chem- Eur J 2003;9:4055-4067.

11. Hanzlik RP, Hogberg K, Moon JB, Judson CM. J Am Chem Soc 1985;107:7164-7167.

12. Cook PF, Oppenheimer NJ, Cleland WW. Biochemistry 1981;20:1817-1825. [PubMed: 7013802]

13. Hermes JD, Morrical SW, O'Leary MH, Cleland WW. Biochemistry 1984;23:5479-5488. [PubMed: 6391544]

14. Huskey WP, Schowen RL. J Am Chem Soc 1983;105:5704-5706.

15. Bell, R. P. The Tunnel Effect in Chemistry; Chapman \& Hall: New York, 1980.

16. Klinman, J. P. In Enzyme Mechanism from Isotope Effects; Cook, P. F., Ed.; CRC Press: Boca Raton, FL, 1991; pp 127-148.

17. Kohen A, Klinman JP. Chem Biol 1999;6:191-198.

18. Bell RP. Chem Soc Rev 1974;3:513-544.

19. Kin Y, Kreevoy MM. J Am Chem Soc 1992;114:7116-7123.

20. Schneider ME, Stern MJ. J Am Chem Soc 1972;94:1517-1522.

21. Kohen A, Klinman JP. Acc Chem Res 1998;31:397-404. 


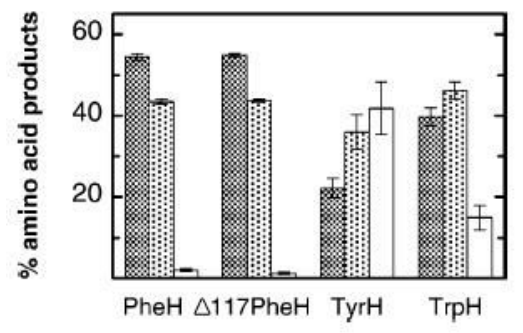

Figure 1.

Product distribution with 4- $\mathrm{CH}_{3}$-phenylalanine as substrate for the aromatic amino acid hydroxylases: 4- $\mathrm{HOCH}_{2}$-phenylalanine (dark gray), 3- $\mathrm{CH}_{3}-4-\mathrm{HO}$-phenylalanine (light gray), and 3-HO-4- $\mathrm{CH}_{3}$-phenylalanine (white). Reactions were carried out and the products analyzed by HPLC as described in ref ${ }^{6}$. Conditions: $25 \mathrm{mM}$ sodium phosphate buffer, $\mathrm{pH} 7.0,30 \mu \mathrm{M}$ ferrous ammonium sulfate, $1.2 \mathrm{mM} 4-\mathrm{CH}_{3}$-phenylalanine, $10 \mu \mathrm{M}$ enzyme, and $150 \mu \mathrm{M} 6$ methyltetrahydropterin at $30^{\circ} \mathrm{C}$. 


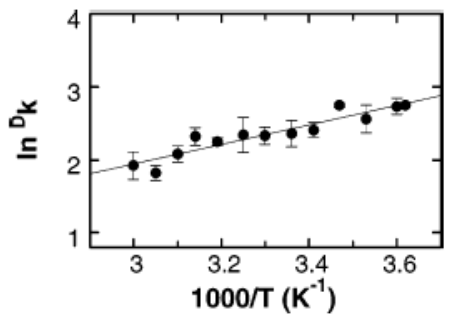

Figure 2.

Deuterium kinetic isotope effects for benzylic hydroxylation as a function of temperature for $\Delta 117 \mathrm{PheH}$. Isotope effects were determined from the effects on product composition with 4$\mathrm{C}^{2} \mathrm{H}_{3}$-phenylalanine. The line is from a fit to the Arrhenius equation. 


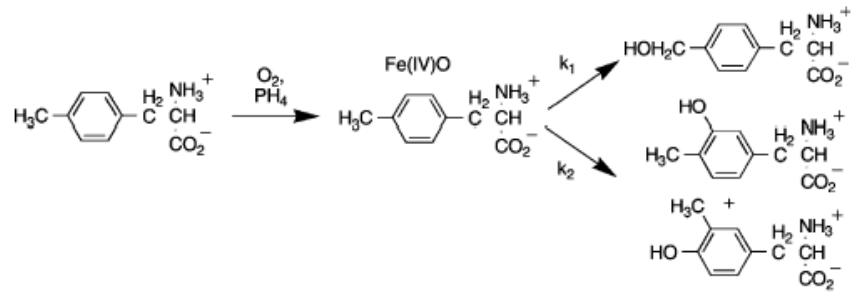

Scheme 1.

$J$ Am Chem Soc. Author manuscript; available in PMC 2006 January 31. 
Table 1

Intrinsic Isotope Effects on Benzylic Hydroxylation by the Aromatic Amino Acid Hydroxylases ${ }^{a}$

\begin{tabular}{|c|c|c|c|c|c|}
\hline substrate & isotope effect & PheH & ه117PheH & WT TyrH & $\operatorname{TrpH}_{102-416}$ \\
\hline \multirow{3}{*}{$\begin{array}{l}\text { 4- } \mathrm{C}^{2} \mathrm{H}_{3} \text {-phe } \\
\text { 4- } \mathrm{CH}_{2}{ }^{2} \mathrm{H} \text {-phe }\end{array}$} & $\mathrm{D}_{k_{1}} b$ & $12.4 \pm 1.1$ & $12.1 \pm 1.1$ & $13.8 \pm 1.2$ & $13.0 \pm 1.7$ \\
\hline & $\mathrm{D}_{k} c$ & $\mathrm{ND}^{d}$ & $9.5 \pm 0.4$ & $9.5 \pm 0.6$ & $10.9 \pm 0.4$ \\
\hline & $\alpha \mathrm{D}_{k} c$ & ND & $1.12 \pm 0.05$ & $1.20 \pm 0.08$ & $1.09 \pm 0.03$ \\
\hline \multirow{2}{*}{ 4- $\mathrm{CH}^{2} \mathrm{H}_{2}$-phe } & $\mathrm{D}_{k} c$ & ND & $7.1 \pm 0.2$ & $7.6 \pm 0.3$ & $7.5 \pm 0.1$ \\
\hline & $\alpha \mathrm{D}_{k} c$ & ND & $1.31 \pm 0.03$ & $1.35 \pm 0.05$ & $1.31 \pm 0.02$ \\
\hline
\end{tabular}

$a_{\text {Conditions as in Figure } 1 .}$

${ }^{b}$ Determined from the difference in product distribution with 4- $\mathrm{CH}_{3}-$ and $4-\mathrm{C}^{2} \mathrm{H}_{3}$-phe using eq 1.

${ }^{c}$ Determined from the difference in $\mathrm{H}$ or ${ }^{2} \mathrm{H}$ loss by mass spectrometry as described in ref 6 .

$d_{\text {Not determined. }}$ 
Table 2

Isotope Effects on Pre-exponential Factors and Differences in Activation Energies for Benzylic Hydroxylation by the Aromatic Amino Acid Hydroxylases ${ }^{a}$

\begin{tabular}{|c|c|c|}
\hline enzyme & $A_{\mathrm{H}} / A_{\mathrm{D}}$ & $\Delta E_{\text {act }}(\mathrm{kcal} / \mathrm{mol})$ \\
\hline $\begin{array}{l}\text { PheH } \\
\Delta 117 \mathrm{PheH} \\
\text { TyrH } \\
\text { TrpH }_{102-416}\end{array}$ & $\begin{array}{l}0.18 \pm 0.08 \\
0.13 \pm 0.06 \\
0.11 \pm 0.05 \\
0.10 \pm 0.05\end{array}$ & $\begin{array}{l}2.4 \pm 0.3 \\
2.6 \pm 0.3 \\
2.9 \pm 0.3 \\
2.9 \pm 0.3\end{array}$ \\
\hline
\end{tabular}

${ }^{a}$ Conditions as described for Figures 1 and 2. 